\title{
The Influence of Biochar Production on Herbicide Sorption Characteristics
}

\author{
S.A. Clay and D.D. Malo \\ South Dakota State University, Plant Science Dept. \\ Brookings, South Dakota
}

USA

\section{Introduction}

Biochar is the by-product of a thermal process conducted under low oxygen or oxygen-free conditions (pyrolysis) to convert vegetative biomass to biofuel (Jha et al., 2010). There are a wide variety of end-products that can be manufactured depending on processing parameters and initial feedstocks (Bridgewater, 2003). The pyrolytic process parameters such as temperature, heating rate, and pressure can change the recovery amounts of each end-product, energy values of the bio-oils, and the physico-chemical properties of biochar (Yaman, 2004).

Biochars are recalcitrant forms of carbon and, depending on properties, can remain in the soil for greater than 1000 years (Skjemstad et al., 2002). The long-term persistence of this carbon form is due to slow microbial degradation and chemical oxidation rates (Sanchez et al., 2009). In addition, biochar interacts with soil materials such as ions, organic matter, and clays that generally increase the persistence of biochar within the soil. However, biochars, unlike commercial fertilizers, are not precisely defined materials and vary widely in properties depending on organic material source and manufacturing process (Karaosmanoglu et al., 2000; McHenry, 2009; Sohi et al., 2010). Increasing pyrolytic temperature decreases biochar recovery but increases $C$ concentration of the char compared with char recovered at lower temperatures (Daud et al., 2001; Katyal et al., 2003). For example, as temperature increased from $300^{\circ}$ to $800^{\circ} \mathrm{C}$, biochar $\mathrm{C}$ content increased from 56 to $93 \%$ whereas biochar yield decreased from 67 to 26\% (Okimori et al., 2003). Other pyrolytic parameters, such as sweep gas flow, can influence biochar particle size with higher flows reducing the particle size but increasing heating values (Katyal et al., 2003; Demirbas, 2004). Biochar also can be influenced by reactor design and other reaction parameters including heating rate, residence time, pressure, and catalyst used. Feedstock type, quality, and initial physical characteristics of the material (e.g. particle size, shape, and structure) can impact the bio-oil yield and properties, as well as the type and amounts of biochar formed (Bridgewater et al., 1999).

Landspreading biochar for a soil amendment is suggested to improve crop production efficiency because regardless of the initial manufacturing process, biochars have a high charge density and surface area. The use of biochar as a soil amendment is not a new concept. Dark earths (terra preta) discovered in the Amazon Basin were found to have 
received deliberate land applications of charred materials and residues of biomass burning by Amer-indian populations before European arrival (Erickson, 2003; Sombroek et al. 2003). Pyrogenic $C$ in terra preta is very resistant to microbial decay over centuries due to its complex aromatic structure and acts as a significant C sink (Glaser et al., 2001).

The benefits of biochar application have been hypothesized to include: increasing plant available soil water; building soil organic matter; enhancing nutrient cycling; lowering soil bulk density; acting as a liming agent if high in $\mathrm{pH}$; and reducing transfer of pesticides and nutrients to surface and ground water (Laird, 2008) thereby improving water quality. The application of biochar to soil has been reported to have a positive impact on physical properties such as soil water retention and aggregation (Piccolo et al., 1996) and may decrease erosion potential. Glaser et al. (2002) observed an increase in field water holding capacity by $18 \%$ in charcoal enriched Anthrosol due to an increase in surface area. Biochar application has been shown to improve other soil physical, chemical, and biological properties (Glaser et al., 2002; Lehmann and Rondon, 2006) leading to positive impacts on plant growth and development. For example, Chidumayo (1994) observed enhanced seed germination $(30 \%)$, shoot height $(24 \%)$, and biomass production $(13 \%)$ of seven indigenous woody crops with the application of charcoal compared with the crops on undisturbed Zambian Alfisols and Ultisols. Kishimoto and Sugiura (1985) also found increases in height (26 to $35 \%$ ) and biomass (2.3 X greater) production of sugi trees (Cryptomeria japonica L.). Similar enhancement was observed in yields of annual crops such as maize (Zea mays L.) on Nigerian Alfisols and Inceptisols with the application of charcoal (Mbagwu and Piccolo, 1997) due to an increase of soil $\mathrm{pH}$ that resulted in greater micro-nutrient availability and decreased deficiencies. However, biochars also have been shown to have an extreme affinity for essential plant nutrients (Sanchez et al., 2009) that can provide a slow release mechanism.

Some biochars that have high $\mathrm{pH}$ (e.g. >9.5) can provide liming capacity and increase the soil pH (Sanchez et al., 1983; Mbagwu and Piccolo, 1997). For example, application of coal ash at the rate of $110 \mathrm{Mg} \mathrm{ha}^{-1}$ increased the $\mathrm{pH}$ of an eroded Palouse soil from 6.0 to 6.8 (Cox et al., 2001). Exchangeable bases also were observed to increase in sandy and loamy soils with the additions of hardwood and conifer charcoals (Tryon, 1948). Application of charcoal to highly weathered soils with low-ion retention capacities increased the cation exchange capacity (CEC) by 50\% compared to unamended soil (Mbagwu and Piccolo, 1997). Oguntunde et al. (2004) reported a significant increase in soil $\mathrm{pH}$, base saturation, electrical conductivity (EC), exchangeable $\mathrm{Ca}, \mathrm{Mg}, \mathrm{K}, \mathrm{Na}$, and available $\mathrm{P}$ in charcoal kiln sites and reported an increase in grain and biomass yield of maize of $91 \%$ and $44 \%$ respectively, with a coal char application. Leaching of $\mathrm{NH}_{4}{ }^{+}$from an unfertilized Ferralsol was reduced with the application of charcoal due to its high $\mathrm{C}$ content, although the retention properties of chars may differ for other ionic species (e.g. $\mathrm{K}, \mathrm{Ca}, \mathrm{Mg}$ ) if the char already contains high concentrations of the ion of interest (Lehmann et al., 2002). Because of biochar's diverse properties and potential for high reactivity in soils, a 'one-recommendation-fits-all situations' mentality for the use as of biochar as a soil amendment needs to be avoided. To date, the greatest positive impacts of biochar have been primarily observed on degraded soils and those with low fertility whereas applications on highly productive soils have been reported to have low or minimal impacts (Woolf et al., 2010).

Agrichemicals such as pesticides, growth regulating chemicals, and nutrients are applied to crops to control pests and increase yield potential. Depending on the type and amount of 
biochar applied, the changes in soil properties associated with the application (e.g. soil pH, EC) as well as the physio-chemical properties of the char itself, may impact the use, rates, efficacious properties, and fates of agrichemicals used in agronomic management. The environmental fate (e.g. leachability, rate of decomposition, etc.) and efficacy of soil applied pesticides are influenced strongly by their reaction and retention with soil particles and organic matter (Brown et al., 1995). Agrichemical molecules can be removed from soil solution through attraction or attachment to the surfaces of organic materials and soil particles (adsorption) or movement into the matrix (like water into a sponge) (absorption). Often, experiments cannot distinguish between these processes so that the general term sorption is used.

Sorption is controlled by properties of the chemical of interest including the water solubility, $\mathrm{pH}$, dissociation constant ( $\mathrm{pKa})$, octanol/water partition coefficient, and other factors (Weber, 1995) and can be used to help describe the fate of an herbicide in the environment (Wauchope et al., 2002). The sorption of the chemical also is affected by soil properties including water, organic matter, clay, sand, and oxide contents, and soil pH (Koskinen and Clay, 1997; Laird and Koskinen, 2008). Soils high in sand generally sorb much less chemical than loamy or clay type soils. Agricultural practices that involve modifying soil organic matter content often increase chemical retention. Indeed, studies have shown that adding biochar to soil can result in greater sorption of pesticides (Cao et al., 2009; Spokas et al., 2009; $\mathrm{Yu}$ et al., 2009). The distribution of chemical between a solution and solid phase gives an indication of the amount of chemical available in solution and is defined using a sorption coefficient $\left(K_{d}\right)$ where:

$$
\mathrm{K}_{\mathrm{d}}=\frac{\text { mass of herbicide sorbed per } \mathrm{g} \text { of solid }}{\text { amount of chemical remaining in solution at equilibrium }}
$$

Large $K_{d}$ values (typically over 100) indicate that a high amount of the chemical originally in solution is sorbed to the solid interface, with low amounts of chemical remaining in solution. Sorption of a chemical from the liquid phase of soil may result in the chemical being: 1) less available to plants, so there may be less uptake; 2) less available to soil organisms, thereby increasing the chemical's residence time and slowing degradation; and 3) less available to leach with water percolating through the soil, which could result in improved groundwater quality.

The biochar source-processing combination provides a rich diversity of biochars to evaluate for soil amendment use (Lehmann et al., 2009). The potential of a specific biochar for a specific use will depend on the physical and chemical properties of the biochar, as well as soil characteristics. The challenge of amending soil with biochar is to identify the benefits that biochar can provide (e.g. fertility, increased water holding capacity) (Lehmann, 2007) and balance these against any negative effects that the char may have. Site-specific application recommendations of specific biochars require an examination of the products of different production and processing scenarios. Much of the biochar research has been based on slow pyrolysis with a goal to optimize biochar properties for a specific goal such as improved soil fertility, greenhouse gas mitigation, or heating value. Little work has been done with biochar produced from fast pyrolysis processes and even less with biochar produced from microwave pyrolysis reactors. 
Feedstock is a key factor governing the status of physio-chemical properties of biochar. All types of materials including, but not limited to, palm shells, rapeseed (Brassica rapa) stems, sunflower (Helianthus annuus), and wood have been used or are being proposed as potential feedstock sources for use in the biofuel industry. In the Midwestern U.S., maize stover and switchgrass (Panicum virgatum) biomass are feedstocks that bioenergy companies are exploring for use.

\section{Biochar influence on herbicide sorption to soil}

This study examined atrazine and 2,4-D sorption to several biochars that were the result of microwave pyrolysis using varying temperatures and processing times of maize and switchgrass biomass. In addition, sorption characteristics of these two chemicals to soil amended with these biochars at two application rates were determined.

\subsection{Materials and methods}

\subsubsection{Biochar and soil}

Biochar was produced from maize stover (stalks and other residues remaining after maize grain harvest) and switchgrass biomass collected from fields near Brookings, South Dakota, USA (44.31, -96.67). Briefly, the material was dried at room temperature and pulverized mechanically using a Thomas-Wiley laboratory mill (Model No. 3375-E15, Thomas Scientific, USA) to pass through a $4 \mathrm{~mm}$ screen. The ground materials were processed by microwave pyrolysis using the SDSU Ag and Biosystem Eng. Dept. microwave system (specific processing methods reported in Lei et al., 2009). Processing temperatures ranged from $530^{\circ}$ to $670^{\circ} \mathrm{C}$ and microwave residence times ranged from 8 to 24 minutes with seven maize and nine switchgrass biochars produced (Table 1 and Figures 1 and 2). The energy output, product types, particle size distribution, and elemental analysis of the biochar recovered from maize stover using these processing conditions are reported in Lei et al. (2009).

For this study, the maize biochars were used alone or mixed with the A horizon soil of a Brandt silty clay loam (Fine-silty, mixed, superactive, frigid Calcic Hapludoll, [Soil Survey Staff, 2011]) soil at 1 or $10 \%(\mathrm{w} / \mathrm{w})$ to examine their effect on solution $\mathrm{pH}, \mathrm{EC}$, and atrazine and 2,4-D $\mathrm{K}_{\mathrm{d}} \mathrm{S}$ (sorption coefficients) for each biochar and biochar/soil combination. For switchgrass biochars, the 1 or $10 \%$ amendments to soil were used for $\mathrm{pH}$ and EC measurements, however, for herbicide sorption studies only biochar alone or soil mixed with $10 \%$ biochar were used, due to limited biochar supply. To maximize homogeneity, each soil/biochar combination was individually mixed by adding air-dry soil and biochar to each individual tube.

\subsubsection{Solution characteristics}

Biochars, soil, and soil with biochar amendments were analyzed for $\mathrm{pH}$ using a $0.01 \mathrm{M}$ $\mathrm{CaCl}_{2}$ slurry $(1: 1 \mathrm{w} / \mathrm{v})$ and a standardized $\mathrm{pH}$ electrode. The solution $\mathrm{pH}$ was recorded after the reading had stabilized. Electrical conductivity (EC) was determined on a slurry that was mixed 1:1 (v/w) with $0.01 \mathrm{M} \mathrm{CaCl}_{2}$ and biochar, soil, or soil amended with biochar. The slurry was shaken for $0.5 \mathrm{hr}$ and EC measured using a commercially available EC electrode. 


\subsubsection{Herbicide sorption}

Atrazine solution was diluted to a final concentration of $13 \mu \mathrm{M}$ in $0.01 \mathrm{CaCl}_{2}$ using technical grade atrazine. This solution was spiked with about $0.4 \mathrm{kBq}$ of uniformly-ring-labeled $\left[{ }^{14} \mathrm{C}\right]$ atrazine (specific activity of $1000 \mathrm{MBq} \mathrm{mmol}^{-1}$ with $>99 \%$ purity; Sigma Chemical Co., St. Louis, MO). The 2,4-D solution was made in a similar manner, with technical grade 2,4-D added to $0.01 \mathrm{M} \mathrm{CaCl}_{2}$ to have a final concentration of $13 \mu \mathrm{M}$. This solution was spiked with uniformly-ring-labeled [ $\left.{ }^{14} \mathrm{C}\right]-2,4-\mathrm{D}$ (specific activity of $1000 \mathrm{MBq} \mathrm{mmol}-1$ with $>99 \%$ purity; Sigma Chemical Co., St. Louis, MO).

A 4-mL aliquot of herbicide solution was added to $2 \mathrm{~g}$ soil or soil amended with 1 or $10 \%$ biochar (final slurry solution 2:1 v/w) in glass centrifuge tubes sealed with a Teflon-lined cap. A 5-mL aliquot of herbicide solution was added to $0.5 \mathrm{~g}$ biochar when biochar was used as the sorbent, with the final solution/biochar ratio of was $10: 1 \mathrm{v} / \mathrm{w}$, due to the highly sorbent characteristics of the biochar.

After solution addition, the mixtures were shaken or vortexed to form a slurry. Tubes containing the slurries were shaken for $24 \mathrm{hr}$, centrifuged, and a $250-\mu \mathrm{L}$ aliquot of supernatant removed. The amount of ${ }^{14} \mathrm{C}$ remaining in the supernatant solution was determined by liquid scintillation (Packard Model 1600TR) counting after the addition of scintillation cocktail. The amount of radioactivity sorbed was determined by comparing the counts in the supernatant samples with counts recorded from the original soil-free blank solution samples. The sorption coefficients $(\mathrm{Kd})$ of the samples were then calculated as $\mathrm{L} \mathrm{kg}^{-1}$, correcting for the differences in volume added $\mathrm{g}^{-1}$ of material.

\subsubsection{Statistical analysis}

Experimental treatments were run in triplicate and studies were repeated in time. Results were combined for the studies due to similarity of means and homogeneity of variance between studies. Means presented were averaged over all treatment replicates and statistically separated by least significant difference calculation at $\mathrm{P} \leq 0.05$.

\subsection{Results}

\subsubsection{Biochar $\mathrm{pH}$ and EC values}

The biochars produced in this study ranged in $\mathrm{pH}$ from acidic (4.06) to alkaline (9.88), and were dependent on feedstock, pyrolysis temperatures, and processing times (Table 1). Differences were observed among maize and switchgrass feedstocks. For maize stover, three of the microwave pyrolysis reactions at high temperatures $\left(\geq 650^{\circ} \mathrm{C}\right)$, regardless of processing time, resulted in biochars that were very alkaline $(\mathrm{pH}>9)$. Two processes at lower temperatures $\left(530^{\circ} \mathrm{C}\right.$ and a processing time of $16 \mathrm{~min}$ or $550^{\circ} \mathrm{C}$ with a processing time of 10 min) resulted in biochars with $\mathrm{pH}<5$. The 22 min processing time at $550^{\circ} \mathrm{C}$ resulted in a biochar with a more neutral (7.6) $\mathrm{pH}$. For switchgrass, four processes resulted in biochars that were acidic $(\mathrm{pH}<4.6)$ and the biochars were more acidic than biochars from maize at the same time and temperature. The acidic biochars were formed from processes that had low temperatures $\left(<600^{\circ} \mathrm{C}\right)$ or shorter times at $600^{\circ} \mathrm{C}(8 \mathrm{~min})$, or $10 \mathrm{~min}$ at $650^{\circ} \mathrm{C}$. The most alkaline switchgrass biochar was the result of processing at $670^{\circ} \mathrm{C}$ for $16 \mathrm{~min}$. This biochar had a $\mathrm{pH}$ of $\sim 9.1$, which was lower than the alkaline maize biochars that ranged in $\mathrm{pH}$ from 


\begin{tabular}{|c|c|c|c|c|c|c|c|}
\hline \multirow{2}{*}{\multicolumn{2}{|c|}{$\begin{array}{c}\text { Pyrolysis } \\
\text { parameters }\end{array}$}} & \multicolumn{6}{|c|}{ Maize (Zea mays) } \\
\hline & & \multicolumn{3}{|c|}{$\mathrm{pH}$} & \multicolumn{3}{|c|}{$\mathrm{EC}$} \\
\hline Temp & time & Biochar & $\begin{array}{c}\text { soil }+ \\
1 \% \\
\text { biochar }\end{array}$ & $\begin{array}{c}\text { soil + } \\
10 \% \\
\text { biochar }\end{array}$ & Biochar & $\begin{array}{c}\text { soil }+ \\
1 \% \text { biochar }\end{array}$ & $\begin{array}{c}\text { soil }+ \\
10 \% \text { biochar }\end{array}$ \\
\hline${ }^{\circ} \mathrm{C}$ & $\min$ & & & & & $\mathrm{mS} \mathrm{cm}^{-1}$ & \\
\hline 530 & 16 & 4.59 & 6.39 & $5.85^{-}$ & 0.3 & 2.4 & 1.4 \\
\hline \multirow[t]{2}{*}{550} & 10 & 4.77 & 6.38 & $6.04^{-}$ & 2.3 & 1.8 & 2.2 \\
\hline & 22 & 7.60 & 6.47 & $6.61^{+}$ & 1.9 & 1.8 & 1.8 \\
\hline 600 & 8 & 5.68 & 6.44 & 6.44 & 2.1 & 1.8 & 2.0 \\
\hline \multirow[t]{2}{*}{650} & 10 & 9.88 & 6.46 & $6.75^{+}$ & 2.0 & 1.9 & 1.9 \\
\hline & 22 & 9.43 & 6.43 & $6.76^{+}$ & 2.0 & 1.8 & 1.9 \\
\hline \multirow[t]{2}{*}{670} & 16 & 9.65 & 6.43 & $6.73^{+}$ & 1.1 & 1.9 & 1.9 \\
\hline & & \multicolumn{6}{|c|}{ Switchgrass (Panicum virgatum) } \\
\hline 530 & 16 & 5.32 & 6.17 & 6.70 & 0.3 & 1.80 & 1.67 \\
\hline \multirow[t]{2}{*}{550} & 10 & 4.12 & 6.49 & $5.67-$ & 2.1 & 2.13 & 1.97 \\
\hline & 22 & 4.06 & 6.49 & $5.71^{-}$ & 1.5 & 1.87 & 2.13 \\
\hline \multirow[t]{3}{*}{600} & 8 & 4.15 & 6.60 & $5.90^{-}$ & 1.9 & 1.80 & 1.83 \\
\hline & 16 & 6.47 & 6.45 & $6.76^{+}$ & 1.7 & 1.30 & 1.33 \\
\hline & 24 & 5.60 & 6.61 & 6.44 & 1.8 & 1.67 & 1.87 \\
\hline \multirow[t]{2}{*}{650} & 10 & 4.57 & 6.44 & $6.11^{-}$ & 2.0 & 2.07 & 2.20 \\
\hline & 22 & 8.28 & 6.48 & $6.80^{+}$ & 2.9 & 1.97 & $2.37^{+}$ \\
\hline 670 & 16 & 9.10 & 6.48 & $6.85^{+}$ & 2.5 & 1.67 & 1.90 \\
\hline
\end{tabular}

Table 1. The influence of seven maize stover and nine switchgrass biochars produced with microwave pyrolosis with different processing times and temperature conditions on $100 \%$ biochar and soils amended with $1 \%$ or $10 \%(\mathrm{w} / \mathrm{w})$ biochar. The soil used for this study was the A horizon of a Brandt silty clay loam (Fine-silty, mixed, superactive, frigid Calcic Hapludoll, [Soil Survey Staff, 2011]) from Aurora, SD (44.31, -96.67) with an unamended pH in a 1:1 solution of $0.01 \mathrm{M} \mathrm{CaCl}_{2}$ of about 6.40 and an $\mathrm{EC}$ value of $1.63 \mathrm{mS} \mathrm{cm}^{-1}$. A '-' sign indicates significantly lower value and $\mathrm{a}^{\text {' }}+$ ' sign indicates significantly higher value compared with unamended soil.

$\sim 9.4$ to 9.9. The $\mathrm{pH}$ of these biochars can be compared with other biochar data. A wood ash/biochar that was the by-product of a commercial ethanol plant (Chippewa Valley Ethanol Company, Benson, MN) was obtained and used for comparison purposes. The wood ash had a $\mathrm{pH}$ of over 11. In comparison, broiler litter biochar obtained from pyrolysis reactions at either 350 or $700^{\circ} \mathrm{C}$ was found to have a fairly uniform acidic $\mathrm{pH}$ (5.5) (Uchimiya et al., 2010). These data indicate that the $\mathrm{pH}$ of different types of biochar are dependent on processing time, temperature, and initial feedstock material. 

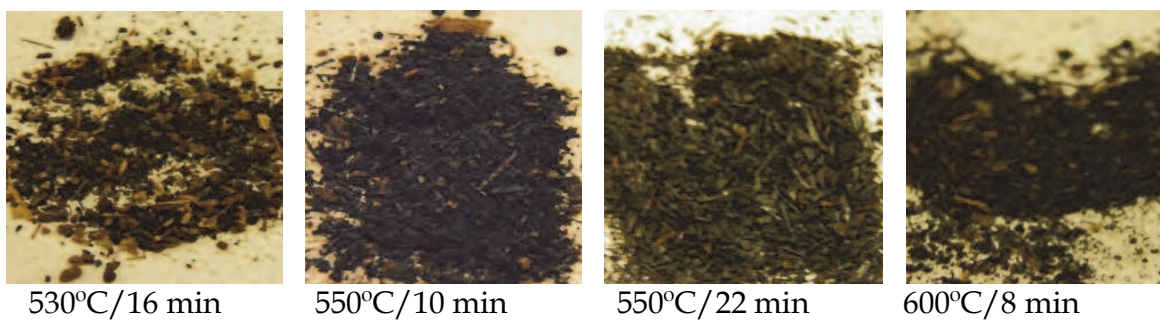

$550^{\circ} \mathrm{C} / 22 \mathrm{~min}$

$600^{\circ} \mathrm{C} / 8 \mathrm{~min}$
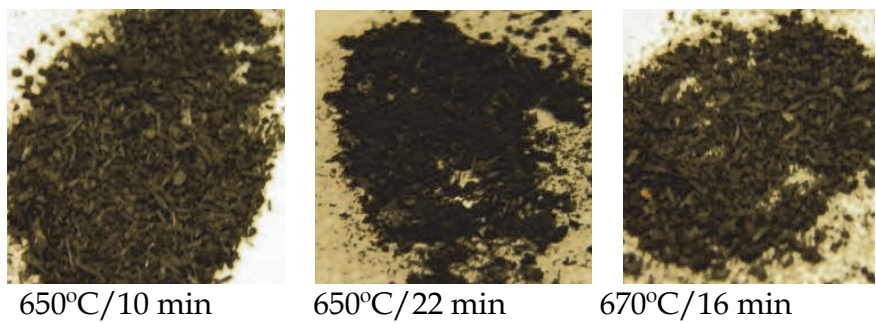

Fig. 1. Examples of biochars formed after exposure of maize (Zea mays) stover feedstocks to microwave pyrolosis at varying temperatures and times (see Lei et al., 2009).

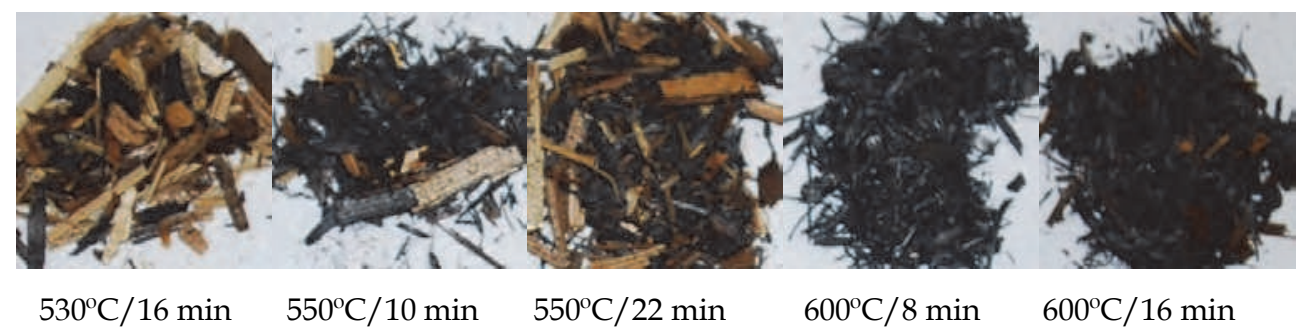

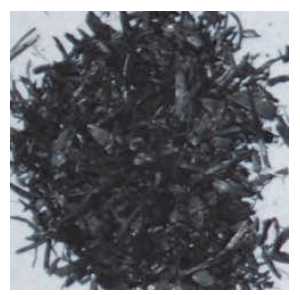

$600^{\circ} \mathrm{C} / 24 \mathrm{~min}$

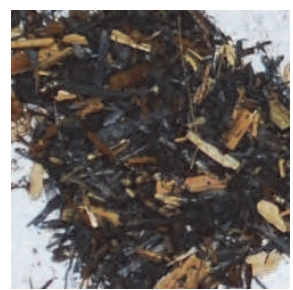

$650^{\circ} \mathrm{C} / 10 \mathrm{~min}$

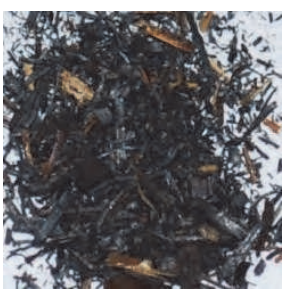

$650^{\circ} \mathrm{C} / 22 \mathrm{~min}$

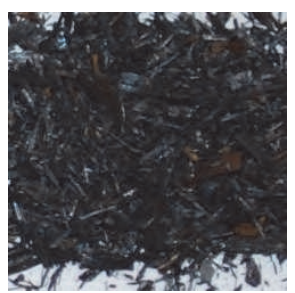

$670^{\circ} \mathrm{C} / 16 \mathrm{~min}$

Fig. 2. Examples of biochars formed after exposure of switchgrass (Panicum virgatum) feedstocks to microwave pyrolosis at varying temperatures and times.

Electrical conductivity provides an indication of the amount of neutral soluble salts in the material or its salinity. High soil salinity often impedes the growth of most agricultural plants. Adding amendments that increase soil salinity, even though other beneficial 
properties such as water holding capacity would increase, would be counterproductive. Saline soils are recognized worldwide (Food and Agriculture Organization, FAO) as soils with an EC reading of $>4 \mathrm{mS} \mathrm{cm}^{-1}$ (Richards, 1954; Abrol et al., 1988). In the U.S., the Soil Science Society of America (SSSA) uses a value of $>2 \mathrm{mS} \mathrm{cm}^{-1}$ boundary for the saline classification. Woodchip biochar had an EC value of $3.6 \mathrm{mS} \mathrm{cm}-1$. Biochar produced from maize stover had EC values ranging from 1.1 to $2.3 \mathrm{mS} \mathrm{cm}^{-1}$ with five out of the seven >1.9 $\mathrm{mS} \mathrm{cm}-1$. The switchgrass biochars had EC values ranging from 1.5 to $2.9 \mathrm{mS} \mathrm{cm}^{-1}$ with the highest EC when materials were processed at $650^{\circ} \mathrm{C}$ for $22 \mathrm{~min}$.

\subsubsection{Influence on biochar amendment on soil pH and EC properties}

The Brandt soil chosen for this study was a silty clay loam with a $\mathrm{pH}$ of 6.4 . Due to the inherent soil properties and buffering capacity of this soil, it was expected that even high applications of the most acidic or alkaline biochar would have minimal impact on soil $\mathrm{pH}$. When $1 \%$ maize or switchgrass biochars were added to soil, $\mathrm{pH}$ changes were minimal (generally <3\%) (Table 1). When soils were amended with $10 \%$ biochar, $\mathrm{pH}$ was influenced to a greater extent. The slurry $\mathrm{pH}$ decreased from 4 to $8 \%$ when low $\mathrm{pH}$ biochars were added and increased a maximum of $9 \%$ when high $\mathrm{pH}$ biochars were added.

Soil EC was $1.63 \mathrm{mS} \mathrm{cm}^{-1}$, well below the salinity values for saline soil. Adding either maize or switchgrass biochar to soil at $1 \%$ increased soil salinity, but with the exception of one switchgrass sample, did not increase the salinity to $>2 \mathrm{mS} \mathrm{cm}^{-1}$. Amending soil with $10 \%$ with the maize biochar that had the greatest EC value $\left(2.3 \mathrm{mS} \mathrm{cm}^{-1}\right)$ was the only maize biochar that increased soil salinity above $2 \mathrm{mS} \mathrm{cm}^{-1}$. Adding switchgrass biochar at $10 \%$ had greater impact than maize stover biochar and increased EC values an average of $11 \%$ when compared with ECs of unamended soil. Three switchgrass biochars increased EC values from 23 to $36 \%$ (Table 1) with final soil slurry EC values above $2 \mathrm{mS} \mathrm{cm}^{-1}$, the SSSA value for saline soil classification. However, even with a $10 \%$ amendment, all final EC values were well below the FAO saline soil value of $4 \mathrm{mS} \mathrm{cm}^{-1}$. If significant amounts of these biochars were applied frequently to the same field, managers must be cognizant of the potential for changes to EC values. Saline soil remediation can be expensive and often requires long-term management interventions, rather than short-term programs.

\subsubsection{Atrazine sorption to biochar and soils amended with biochar}

Atrazine is a chemical in the triazine family and has a slightly positive charge in soil solutions (Laird and Koskinen, 2008). The positive charge on the molecule, when in solutions above its $\mathrm{pK}_{\mathrm{a}}$, causes the molecule to be sorbed to materials that have a negative charge. Atrazine sorption to soil is considered moderate with $K_{d}$ values ranging from 1 to 5 (Koskinen and Clay, 1997). The value is dependent on many soil properties including $\mathrm{pH}$, organic matter, and clay content (Koskinen and Clay, 1997). In this study, atrazine sorption to biochar ranged from 7 to $92 \mathrm{~L} \mathrm{~kg}^{-1}$ (Figure 3). The sorption was dependent on feedstock type and processing method. These values ranged from 200 to $2300 \%$ greater than sorption to soil.

In general, the biochars from maize had much more variability in $\mathrm{K}_{\mathrm{d}}$ values than switchgrass biochar (Figure 3). Three of the seven maize biochars had $\mathrm{K}_{\mathrm{d}} \mathrm{s}$ less than $20 \mathrm{~L} \mathrm{~kg}^{-1}$ whereas the other four had values of $55 \mathrm{~L} \mathrm{~kg}^{-1}$ or greater. In general, the switchgrass biochars had lower 

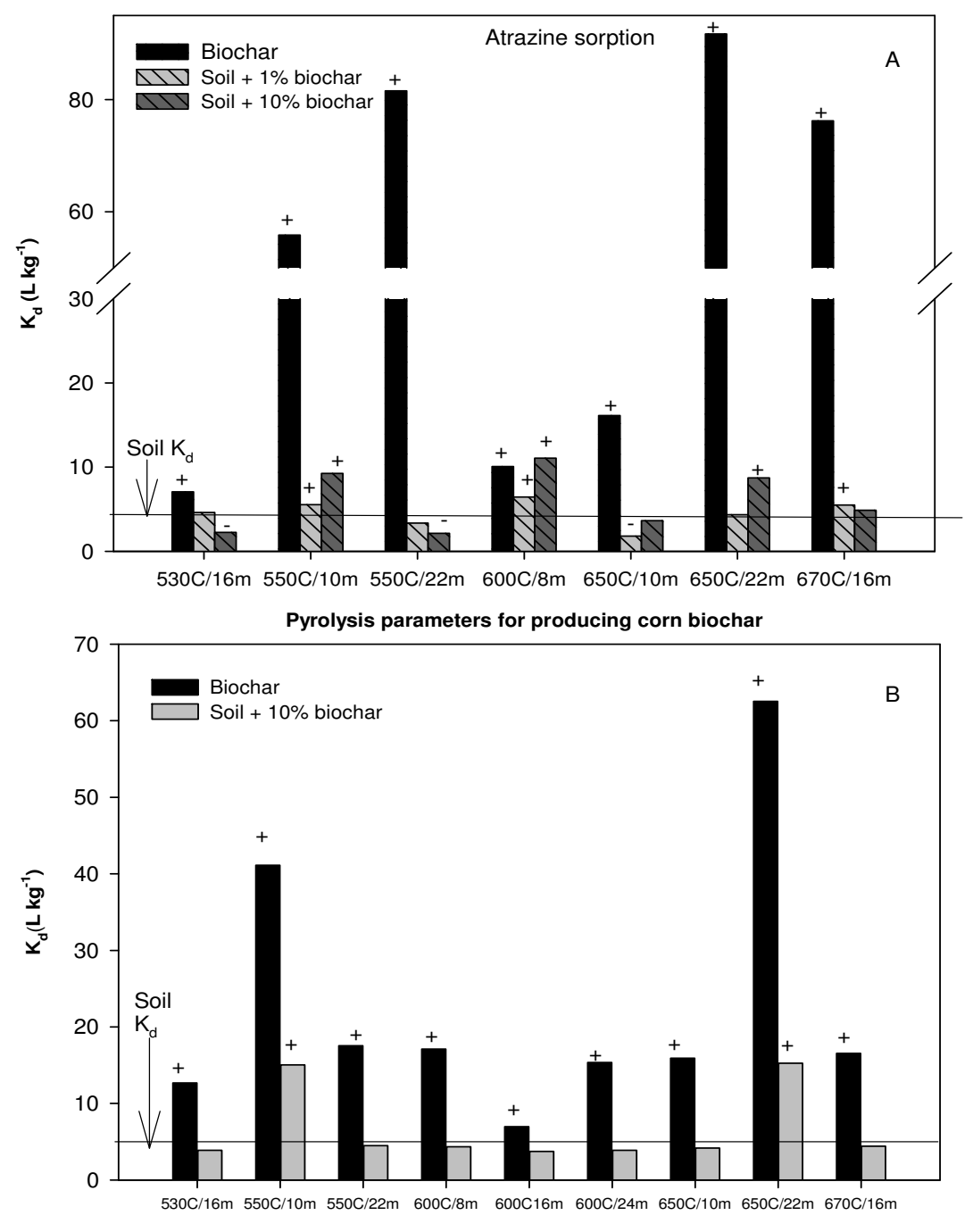

Pyrolysis parameters for producing switchgrass biochar

Fig. $3 \mathrm{~A}$ and B. Atrazine sorption $\left(\mathrm{K}_{\mathrm{d}}\right)$ values to biochar from maize (Zea mays) stover $(\mathrm{A})$ and switchgrass (Panicum virgatum) (B) produced by microwave pyrolysis at various processing times and temperatures. $K_{d}$ values of sorption for the A horizon of a Brandt silty clay loam (Fine-silty, fmixed, superactive, frigid Calcic Hapludoll, [Soil Survey Staff, 2011]) soil when amended with 1 or $10 \%$ maize biochar or $1 \%$ switchgrass biochar. $K_{d}$ sorption value of atrazine to unamended soil averaged about $3.86 \mathrm{~L} \mathrm{~kg}^{-1}$. A “-“ sign indicates lower sorption at $\mathrm{P} \leq 0.05$ and $\mathrm{a}$ " + " sign indicates greater sorption at $\mathrm{P} \leq 0.05$ than unamended soil. 
$K_{d}$ values for atrazine than maize, with only two of the nine samples having sorption values $>18 \mathrm{~L} \mathrm{~kg}^{-1}$. Correlation analysis was conducted to examine $\mathrm{pH}$ of biochar vs $\mathrm{K}_{\mathrm{d}}$ but these parameters were poorly to moderately correlated for maize $(r=0.4)$ and not correlated for switchgrass.

Amending soil with maize biochar at $1 \%$ increased the $K_{d}$ with three biochars and decreased the $\mathrm{K}_{\mathrm{d}}$ for one biochar. The maximum increase was $66 \%$ more sorbed than unamended soil. The $10 \%$ additions decreased the amount sorbed by soil in two samples by about $43 \%$. This was surprising as one of the biochars alone had double the $K_{d}$ of soil $\left(K_{d}=7 \mathrm{~L} \mathrm{~kg}^{-1}\right)$ and a $\mathrm{pH}$ of 4.5 and the other had very high sorption $\left(\mathrm{K}_{\mathrm{d}}=82 \mathrm{~L} \mathrm{~kg}^{-1}\right)$ value and $\mathrm{pH}$ of 7.6. It is unclear what properties of this biochar would result in lower atrazine sorption. The soil amended with three maize biochars used at 10\% amendment had nearly 3 times as much atrazine sorbed $\left(\mathrm{K}_{\mathrm{d}} \mathrm{S}\right.$ ranging from 8.7 to $\left.11.0 \mathrm{~L} \mathrm{~kg}^{-1}\right)$ when compared with soil alone. Two switchgrass biochars with the highest atrazine sorption also increased atrazine sorption when added as a $10 \%$ soil amendment, and raised the $\mathrm{K}_{\mathrm{d}} \mathrm{s}$ nearly 4 -fold, with a $\mathrm{K}_{\mathrm{d}}$ of about $15 \mathrm{~L} \mathrm{~kg}^{-1}$. Other switchgrass biochars had no or only a slight influence on atrazine sorption.

\subsubsection{2,4-D sorption to biochar and soils amended with biochar}

Unlike atrazine which has a positive charge in most soils, 2,4-D with a pKa of 2.8 is a weak acid in most soil solutions (Wauchope et al., 1992). This chemical was chosen as a model compound to explore the effect of biochar on these types of compounds. The negative charge on the 2,4-D, as well as other chemicals in this auxin-type chemistry, often results in low or no sorption to soil (Clay et al., 1988). If these types of chemicals have a long residence time in soil (e.g. picloram), there is a high potential for leaching, although, because 2,4-D often is reported to have a $1 / 2$ life of $10 \mathrm{~d}$ or less, leaching of this chemical is not usually considered a problem.

The $\mathrm{K}_{\mathrm{d}}$ sorption value of 2,4-D to unamended Brandt soil was about $1 \mathrm{~L} \mathrm{~kg}^{-1}$, a four-fold lower sorption than atrazine to this soil. All biochar samples had much greater sorption coefficients than soil alone (Figure 4), with switchgrass biochars generally sorbing more 2,4$\mathrm{D}$ than maize biochars. The $\mathrm{K}_{\mathrm{d}}$ values for all biochars, regardless of feedstock type ranged from about 3 to $>80 \mathrm{~L} \mathrm{~kg}^{-1}$ and was much greater than soil. $\mathrm{K}_{\mathrm{d}}$ values for soil amended with $1 \%$ maize biochars were similar to $K_{d}$ of unamended soil (Figure 4). Amending soil with $10 \%$ biochar (either maize or switchgrass) resulted in a few treatment combinations that had increased sorption compared to soil. Maize biochar resulting from processing stover at $600^{\circ} \mathrm{C}$ for $8 \mathrm{~min}$ increased 2,4-D sorption 3.3 times over unamended soils, whereas maize biochar formed from processing at $650^{\circ} \mathrm{C}$ for $22 \mathrm{~min}$ increased 2,4-D sorption by 4.5 times. Switchgrass biochar added at $10 \%$ to soil had little impact on 2,4-D sorption with two exceptions. The first was the biochar formed when processed at $550^{\circ} \mathrm{C}$ for $10 \mathrm{~min}$ where a 9.4- fold sorption increase was measured and the second when switchgrass was processed at $650^{\circ} \mathrm{C}$ for $22 \mathrm{~min}$ where a 15-fold sorption increase was measured. These two switchgrass biochars also dramatically increased atrazine sorption. The char produced at the higher temperature did influence soil EC values at $10 \%$ addition (Table 1), however, it is not known what the exact properties of these biochars or their interactions with soil/solution resulted in these increased sorption amounts. 


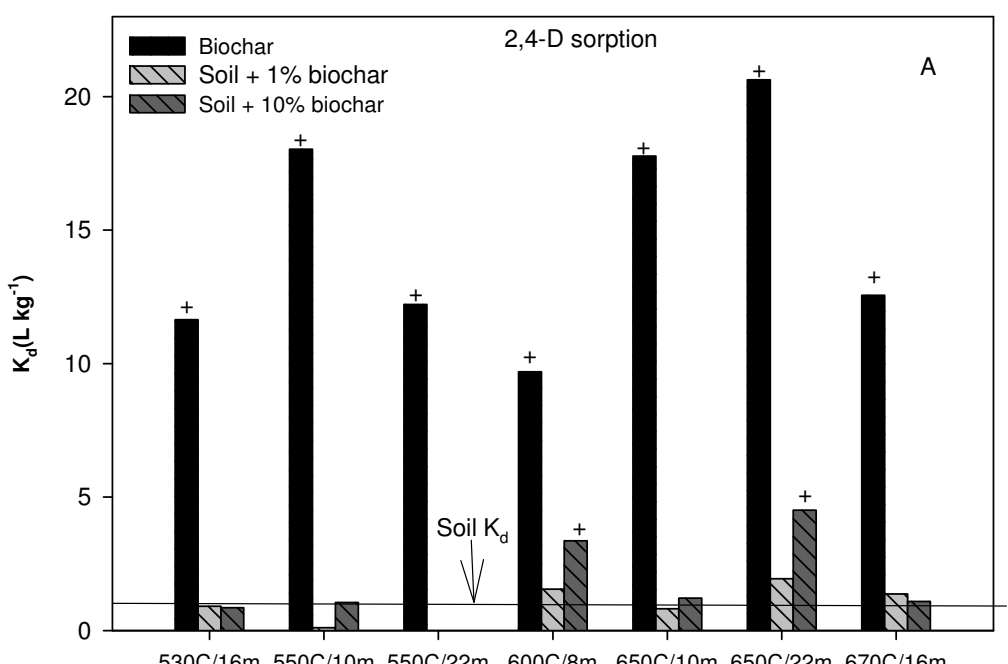

Pyrolysis parameters for producing corn biochar

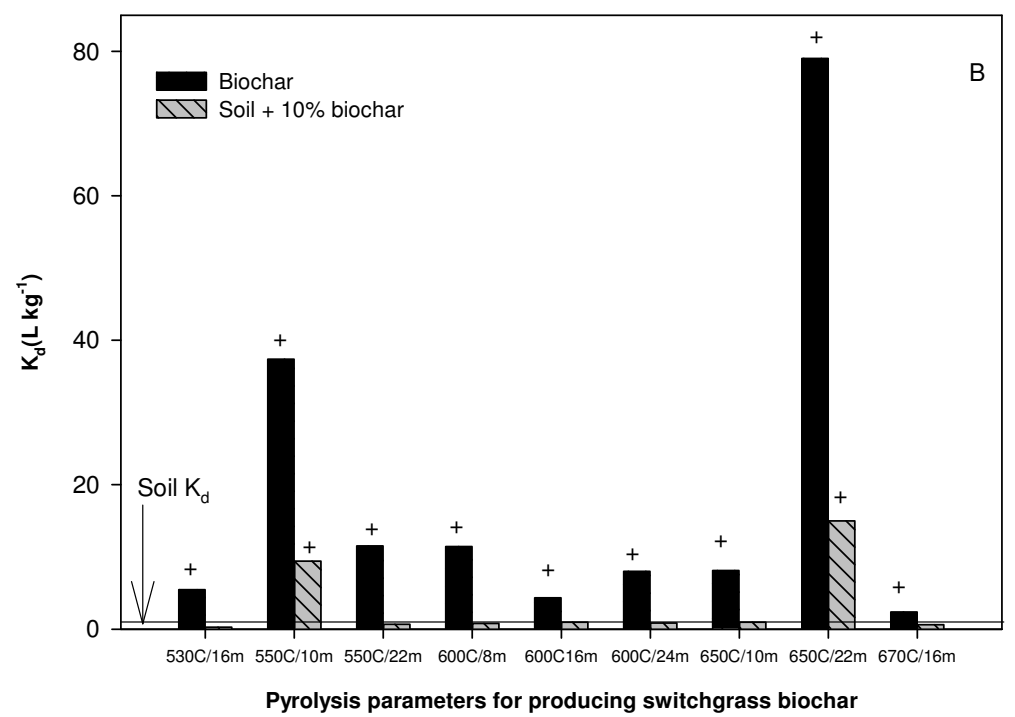

Fig. 4 A and B. 2,4-D sorption $\left(\mathrm{K}_{\mathrm{d}}\right)$ values to biochar from maize (Zea mays)stover and switchgrass (Panicum virgatum) produced by microwave pyrolysis at various processing times and temperatures; $K_{d}$ values of sorption for the A horizon of a Brandt silty clay loam (Fine-silty, mixed, superactive, frigid Calcic Hapludoll, [Soil Survey Staff, 2011]) soil when amended with 1 or $10 \%$ maize biochar or $10 \%$ switchgrass biochar. $K_{d}$ sorption value of unamended soil averaged about $1.0 \mathrm{~L} \mathrm{~kg}^{-1}$. A " + " sign indicates greater sorption at $\mathrm{P} \leq 0.05$ than unamended soil. 


\section{Conclusion}

Biochars, the by-products of pyrolitic conversion processes of vegetative biomass to gas, biooil, or other fuels, are proposed soil amendments for many diverse purposes. Biomass feedstocks and production processes vary depending on the desired end-products. This study measured the influence of several microwave pyrolitic conversion processes, which varied temperature and residence time, on $\mathrm{pH}$ and $\mathrm{EC}$ characteristics of the resulting biochars produced from maize stover and switchgrass. These biochars were used to amend a silty clay loam soil and examined the solution $\mathrm{pH}, \mathrm{EC}$, and sorption properties of a weakly cationic herbicide, atrazine, and an anionic herbicide, 2,4-D.

The microwave pyrolysis parameters of processing time and temperature of maize stover and switchgrass produced biochars that had a range of characteristics, with enough variation that they should not be thought of as a single entity with uniform properties. Short processing times $(<10 \mathrm{~min})$ of either feedstock at high $\left(650^{\circ} \mathrm{C}\right)$ or low $\left(550^{\circ} \mathrm{C}\right)$ temperature resulted in biochar with a $\mathrm{pH}<4.5$. Biochars produced with processing times $>15 \mathrm{~min}$ at high temperature resulted in materials with $\mathrm{pHs}>8$. Processing at intermediate temperatures and times resulted in char $\mathrm{pHs}$ ranging from 5.6 to 6.5 . Adding $1 \%$ char to soil did not impact soil $\mathrm{pH}(6.4)$ whereas adding $10 \%$ biochar decreased soil $\mathrm{pH}$ a maximum of $12 \%$ when low $\mathrm{pH}$ biochars were used or increased soil $\mathrm{pH}$ up to $7 \%$ when high $\mathrm{pH}$ biochars were applied. "Native" soil EC was $1.63 \mathrm{mS} / \mathrm{cm}$. Soils amended with $1 \%$ or $10 \%$ biochar ranged from $-20 \%$ lower up to $39 \%$ higher EC values depending on biochar type and amount added. The biochars used in this study would be considered 'fresh', and not aged or post-process treated. Aging biochar or treating with steam or oxygen has been reported to dramatically change $\mathrm{pH}$ and other properties. Studies on these materials would need to be conducted to determine if results are similar to those reported for this study.

In a 2010 literature review, Kookana (2010) stated that there were limited published studies on the effect of biochars on pesticide efficacy and fate in soil, although in the few studies where sorption is reported, the sorption coefficients could be as high as $>2000$ times those of soil. Results from our study confirmed that when biochars were used as a single sorption material very high sorption amounts could be observed for both a cationic and an anionic compound. Herbicide sorption $\mathrm{K}_{\mathrm{d}}$ to all biochars alone was very high compared with soil but varied among biochar types. Soil amended with $1 \%$ maize stover biochar had herbicide sorption values similar to unamended soil. However, adding $10 \%$ biochar amendment increased both atrazine and 2,4-D sorption coefficients by many-fold. A neutral herbicide, alachlor, has also been shown to have increased sorption in soils amended with woodchip biochar addition (Spokas et al., 2009). If biochars are applied to production fields, biochars may reduce atrazine preemergence weed control due to decreased availability to emerging seedlings. Kookana (2010) also discussed the possibility of longer residence time of pesticides due to reduced bioavailability, which may influence further the impact of a pesticide on ecotoxicology and potential accumulation. Indeed, Jones et al. (2011) reported biochar addition suppressed simazine biodegradation due to limiting availability to soil microbes through increased sorption, although leaching potential was reduced simultaneously.

The results of this study along with other reports have implications on best use of biochar in agricultural fields. If biochar has no or little effect on pesticide sorption, efficacy, or EC values, then the material may be suitable for general application in agricultural fields and 
highly desirable if it can be used to increase water holding capacity or as a nutrient source. Biochars, if high in sorption capacity, may be applied strategically and could accomplish important roles in ecosystem health and environmental quality. Biochar, added in filter strips and waterways, eroded landscapes, or other areas where increased sorption is desired, may aid in cleaning water running off fields by sorbing undesirable contaminants. Increased sorption may also slow or stop herbicides from leaching, so highly sorbent biochar types may be desired over shallow aquifers or in areas low in native organic matter (Wang et al., 2010). Herbicide bioavailability in some cases may be reduced, protecting sensitive plants.

Conversely, the effect of spreading biochars across entire fields may have negative results and be undesirable. One consequence may be that the materials increase soil EC values to saline levels. In addition, if the biochar reduces the efficacy of soil-applied herbicides or other pesticides this may have negative impacts. Reduced pesticide efficacy would require higher herbicide application rates to be as effective as lower rates. This would have monetary implications for growers and field managers by increasing management costs. Increased sorption, in some cases, also may increase the recalcitrance of pesticides leading to longer residence times in the environment. The occurrence of greater recalcitrance may be desirable if bioactivity was still acceptable and longer activity of the pesticide was desired to control the pest of interest. However, longer residence time may lead to other long-term environmental problems, such as greater leaching potential or carry-over problems into the following season.

Prior to any regular field applications of any biochar, the biochar properties must be examined to determine the suitability of the material for the long-term management of a particular site. The reasons for the application should be defined clearly and the outcomes closely monitored to determine if expectations and results are synonymous.

\section{Acknowledgments}

Funding provided by South Dakota Maize Utilization Council, US USDA/Sun Grant Initiative, and South Dakota Agricultural Experiment Station. Undergraduate participation included Mr. Mitch Olson, Mr. Dan Clay, and Ms. Kaitlynn Krack.

\section{References}

Abrol, I.P., Yadav, J.S.P., \& Massoud, F. (1988). Salt affected soils and their management, Food and Agricultural Organization of the United Nations (FAO), Soils Bulletin 39.

Bridgewater, A.V. (2003). Renewable fuels and chemicals by thermal processing of biomass. Chemical Engineering Journal, 91, 2-3, (March 2003), pp. 87-102.

Bridgewater, A.V., Meier, D., \& Radlein, D. (1999). An overview of fast pyrolysis of biomass. Organic Geochemistry, 30, 12, (December1999), pp. 1479-1493.

Brown, C.D., Carter, A.D., \& Hollis, J.M. (1995). Soils and pesticide mobility, In: Environmental Behaviour of Agrochemicals, Roberts, T.R., \& Kearney, P.C. (Eds.). pp. 131-184, John Wiley \& Sons, Chichester, England.

Cao, X., Ma, L., Gao, B., \& Harris, W. (2009). Dairy-manure derived biochar effectively sorbs lead and atrazine. Environmental Science and Technology, 43, 9, (May 2009), pp. 32853291. 
Chidumayo, E. N. (1994). Effects of wood carbonization on soil and initial development of seedlings in miombo woodland, Zambia. Forest Ecology and Management, 70, 1-3, (December 1994), pp. 353-357.

Clay, S.A., Koskinen, W.C., Allmaras, R.R., \& Dowdy, R.H. (1988). Differences in herbicide adsorption on soil using several soil $\mathrm{pH}$ modification techniques. Journal of Environmental Science and Health B. 23, 6, (1988), pp. 599-573.

Cox, D., Bezdicek, D., \& Fauci, M. (2001). Effects of compost, coal ash, and straw amendments on restoring the quality of eroded Palouse soil. Biology and Fertility of Soils, 33, 5, (2001), pp. 365-372.

Daud, W.M.A.W., Ali, W.S.W., \& Sulaiman, M.Z. (2001). Effect of carbonization temperature on the yield and porosity of char produced from palm shell. Journal of Chemical Technology and Biotechnology, 76, 12, (December 2001), pp. 1281-1285.

Demirbas, A. (2004). Effects of temperature and particle size on bio-char yield from pyrolysis of agricultural residues. Journal of Analytical and Applied Pyrolysis, 72, 2, (November 2004), pp. 243-248.

Erickson, C. (2003). Historical ecology and future explorations. In: Amazonian Dark Earths: Origin, Properties, Management, Lehmann, J., Kern, D.C., Glaser, B., \&Woods, W.I. (Eds.), pp. 455-500, Kluwer Academic Publishers, Dordrecht, Netherlands.

Glaser, B., Haumaier, L., Guggenberger, G.\& Zech, W. (2001). The Terra Preta phenomenon - a model for sustainable agriculture in the humid tropics. Naturwissenschaften, 88, 1, (January 2001), pp. 37-41.

Glaser, B., Lehmann, J., \& Zech, W. (2002). Ameliorating physical and chemical properties of highly weathered soils in the tropics with charcoals-A review. Biology and Fertility of Soils, 35, 4, (June 2002), pp. 219-230.

Jha, P., Biswas, A.K., Lakaria, B.L., \& Rao, A.S. (2010). Biochar in agriculture - prospects and related implications. Current Science, 99, 9, (November 2010), pp. 1218-1225.

Jones, D.L., Edward-Jones, G. \& Murphy, D.V. (2011). Biochar mediated alterations in herbicide breakdown and leaching in soil. Soil Biology $\mathcal{E}$ Biochemistry, 43, 4, (April 2011), pp. 804-813.

Karaosmanoglu, F., Isigigur-Ergudenler, A., \& Sever, A. (2000). Biochar from the straw-stalk of rapeseed plant. Energy \& Fuels, 14, 2, (March-April 2000), pp. 336-339.

Katyal, S., Thambimuthu, K., \& Valix, M. (2003). Carbonisation of bagasse in a fixed bed reactor: influence of process variables on char yield and characteristics. Renewable Energy, 28, 5, (April 2003), pp. 713-725.

Kishimoto, S., \& Sugiura, G. (1985). Charcoal as a soil conditioner. In: Symposium on Forest Products Research, International Achievements for the Future, 5, (April 1985), pp.1223 Republic of South Africa.

Kookana, R.S. (2010). The role of biochar in modifying the environmental fate, bioavailability, and efficacy of pesticides in soils: a review. Australian Journal of Soil Research, 48, special issue. 6-7, (June 2010), pp. 627-637.

Koskinen, W. C. \& Clay, S.A. (1997). Factors Affecting Atrazine Fate in North Central U.S. Soils. Reviews of Environmental Contamination and Toxicology, 151, pp. 117-165.

Laird, D.A. (2008). The charcoal vision: A win-win-win scenario for simultaneously producing bioenergy, permanently sequestering carbon, while improving soil and water quality. Agronomy Journal, 100, 1, (January 2008), pp. 178-181. 
Laird, D.A, \& Koskinen, W.C. (2008). Triazine soil interactions. In: The Triazine Herbicides. 50 years revolutionizing agriculture, LeBaron, H.M., McFarland, J.E., \& Burnside, O.C. (Eds.), pp. 275-299. Elsevier, Oxford, UK.

Lehmann, J. (2007). Bio-energy in the black. Frontiers in Ecology and the Environment, 5, 7, (September 2007), pp. 381-387.

Lehmann, J., Czimczik, C., Laird, D., \& Sohi, S. (2009). Stability of biochar in the soil. In: Biochar for Environmental Management, Lehmann, J. \& Joseph, S. (Eds.), pp.183-205, Earthscan, London, England.

Lehmann, C.J., da Silva Jr., J.P., Rondon, M., daSilva, C.M., Greenwood, J. Nehls, T., Stein, C., \& Glaser, B. (2002). Slash-and-char - a feasible alternative for soil fertility management in the central Amazon? Proceedings of 17th World Congress of Soil Science, Bangkok, August, 2002.

Lehmann, C.J., \& Rondon, M. (2006). Bio-char soil management on highly-weathered soils in the tropics. In: Biological Approaches to Sustainable Soil Systems, Uphoff, N.T. (Ed.), pp. 517-530, CRC Press, Boca Raton, FL.

Lei, H., Ren, S., \& Julson, J. (2009). The effects of reaction temperature and time and particle size of maize stover on microwave pyrolysis. Energy E Fuels, 23, 6, (June 2009), pp. 3254-3261.

Mbagwu, J.S.C., \& Piccolo, A. (1997). Effects of humic substances from oxidized coal on soil chemical properties and maize yield. In: The Role of Humic Substances in the Ecosystems and in Environmental Protection, Drozd, J., Gonet, S.S., Senesi, N., Weber, J. (Eds). pp. 921-925, IHSS, Polish Society of Humic Substances, Wroclaw, Poland.

McHenry, M. (2009). Agricultural bio-char production, renewable energy generation and farm carbon sequestration in Western Australia: certainty, uncertainty and risk. Agriculture, Ecosystems and Environment, 129, issues 1-3, (January 2009), pp. 1-7.

Oguntunde, P.G., Fosu, M., Ajayi, A.E., \& van de Giesen, N. (2004). Effects of charcoal production on maize yield, chemical properties and texture of soil. Biology and Fertility of Soils, 39, 4, (March 2004), pp. 295-299.

Okimori, Y., Ogawa, M., \& Takahashi, F. (2003). Potential of $\mathrm{CO}_{2}$ emission reductions by carbonizing biomass waste from industrial tree plantation in Sumatra, Indonesia. Mitigation and Adaptation. Strategies for Global Change, 8, 3, (September 2003), pp. 261-280.

Piccolo, A., Pietramellara, G., \& Mbagwu, J.S.C. (1996). Effects of coal derived humic substances on water retention and structural stability of Mediterranean soils. Soil Use and Management, 12, 4, (December 1996), pp. 209-213.

Richards, L.A. (ed.) 1954. Diagnosis and improvements of saline and alkali soils. USDA. Agriculture Handbook 60.160 p.

Sanchez, M.E., Lindao, E., Margaleff, D., Martinez, O., \& Moran, A. (2009). Pyrolysis of agricultural residues from rape and sunflower: production and characterization of biofuels and biochar soil management. Journal of Analytical and Applied Pyrolysis, 85, 1-2 (May 2009), pp. 142-144.

Sanchez, P.A., Villachia, J.H., \& Bandy, D.E. (1983). Soil fertility dynamics after clearing tropical rainforest in Peru. Soil Science Society of America Journal, 47, 6, (NovemberDecember. 1983), pp. 1171-1178. 
Skjemstad J.O., Reicosky, D.C., Wilts, A.R., \& McGowan, J.A. (2002). Charcoal carbon in U.S. agricultural soils. Soil Science Society of America Journal, 66, 4, (July-August, 2002), pp. 1249-1255.

Sohi, S.P., Krull, E., Lopez-Capel, E., \& Bol, R. (2010). A review of biochar and its use and function in soil. Advances in Agronomy. 105, (2010), pp. 47-82.

Sombroek, W., Ruivo, M.L., \& Fearnside, P.M. (2003). Amazonian dark earths as carbon stores and sinks. In: Amazonian Dark Earths: Origin, Properties, Management, part 2 Lehmann, J., Kern, D. C., Glaser, B., \& Woods, W. I. (Eds.), pp. 125-139, Kluwer Academic Publishers, Dordrecht, Netherlands.

Spokas, K.A., Koskinen, W.C., Baker, J.M., \& Reicosky, D.C. (2009). Impacts of woodchip biochar additions on greenhouse gas production and sorption/degradation of two herbicides in a Minnesota soil. Chemosphere, 77, 4, (October 2009), pp. 574-581.

Soil Survey Staff, Natural Resources Conservation Service, United States Department of Agriculture. Official Soil Series Descriptions. Available online at http://soils.usda.gov/technical/classification/osd/index.html . Accessed August 24, 2011.

Tryon, E.H. (1948). Effect of charcoal on certain physical, chemical, and biological properties of forest soils. Ecological Monographs, 18, 1, (January 1948), pp. 81-115.

Uchimiya, M., Wartelle, L.H., Lima, I.M., \& Klasson, K.T. (2010). Sorption of deisopropylatrazine on broiler litter biochars. Journal of Agriculture and Food Chemistry. 28, 23, (December 2010), pp. 12350-12356.

Wang, H.L., Lin, K.D., Hou, Z.N., Richardson, B., \& Gan, J. (2010). Sorption of the herbicide terbuthylazine in two New Zealand forest soils amended with biosolids and biochars. Journal of Soils and Sediments, 10, 2, (March 2010), pp. 283-289.

Wauchope, R.D., Buttler, T.M., Hornsby, A.G., Augustijn-Beckers, P.W.M., \& Burt, J.P. (1992) The SCS/ARS/CES pesticide properties database for environmental decision-making. Reviews of Environmental Contamination and Toxicology, 123, (1992) pp. 1-155.

Wauchope, R.D., Yeh, S., Linders, J.B.H.J., Kloskowski, R., Tanaka, K., Rubin, B., Katayama, A., Kördel, W., Gerstl, Z.,Lane, M., \& Unsworth, J.B. (2002). Pesticide soil sorption parameters: theory, measurement, uses, limitations and reliability. Pest Management Science, 58, 5 (May, 2002), pp. 419-445.

Weber, J.B. (1995). Physicochemical and mobility studies with pesticides. In: Agrochemical Environmental Fate: State of the Art. Leng, M.L., Leovey, E.M.K., and Zubkoff, P.L. (Eds.), pp. 99-116, CRC Press. Boca Raton, FL.

Woolf, D., Amonette, J.E., Street-Perrott, F.A., Lehmann, J., \& Joseph, S. (2010). Sustainable biochar to mitigate global climate change. Nature Communications, 1, 56, (August 2010), pp. 1-9.

Yaman, S. (2004). Pyrolysis of biomass to produce fuels and chemical feedstocks. Energy Conversion and Management, 45, 5, (March 2004), pp. 651-671.

Yu, X.-Y., Ying, G.-G., \& Kookana, R. S. (2009). Reduced plant uptake of pesticides with biochar additions to soil. Chemosphere, 76, 5, (July 2009), pp. 665-671. 


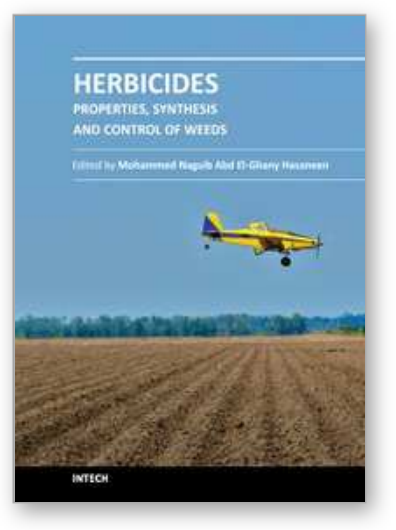

\author{
Herbicides - Properties, Synthesis and Control of Weeds \\ Edited by Dr. Mohammed Nagib Hasaneen
}

ISBN 978-953-307-803-8

Hard cover, 492 pages

Publisher InTech

Published online 13, January, 2012

Published in print edition January, 2012

This book is divided into two sections namely: synthesis and properties of herbicides and herbicidal control of weeds. Chapters 1 to 11 deal with the study of different synthetic pathways of certain herbicides and the physical and chemical properties of other synthesized herbicides. The other 14 chapters (12-25) discussed the different methods by which each herbicide controls specific weed population. The overall purpose of the book, is to show properties and characterization of herbicides, the physical and chemical properties of selected types of herbicides, and the influence of certain herbicides on soil physical and chemical properties on microflora. In addition, an evaluation of the degree of contamination of either soils and/or crops by herbicides is discussed alongside an investigation into the performance and photochemistry of herbicides and the fate of excess herbicides in soils and field crops.

\title{
How to reference
}

In order to correctly reference this scholarly work, feel free to copy and paste the following:

S.A. Clay and D.D. Malo (2012). The Influence of Biochar Production on Herbicide Sorption Characteristics, Herbicides - Properties, Synthesis and Control of Weeds, Dr. Mohammed Nagib Hasaneen (Ed.), ISBN: 978953-307-803-8, InTech, Available from: http://www.intechopen.com/books/herbicides-properties-synthesisand-control-of-weeds/the-influence-of-biochar-production-on-herbicide-sorption-characteristics

\section{INTECH}

open science | open minds

\author{
InTech Europe \\ University Campus STeP Ri \\ Slavka Krautzeka 83/A \\ 51000 Rijeka, Croatia \\ Phone: +385 (51) 770447 \\ Fax: +385 (51) 686166 \\ www.intechopen.com
}

\author{
InTech China \\ Unit 405, Office Block, Hotel Equatorial Shanghai \\ No.65, Yan An Road (West), Shanghai, 200040, China \\ 中国上海市延安西路65号上海国际贵都大饭店办公楼 405 单元 \\ Phone: +86-21-62489820 \\ Fax: +86-21-62489821
}


(C) 2012 The Author(s). Licensee IntechOpen. This is an open access article distributed under the terms of the Creative Commons Attribution 3.0 License, which permits unrestricted use, distribution, and reproduction in any medium, provided the original work is properly cited. 